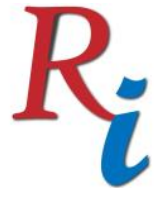

Asia Proceedings of Social Sciences

(APSS)

www.readersinsight.net/APSS

\title{
Innovative Insights into Corporate Social Responsibility Dynamics
}

\author{
Naeem Khan* \\ Foundation University Islamabad, \\ Pakistan \\ Qaisar Ali Malik \\ Foundation University Islamabad, \\ Pakistan
}

*Corrosponding author's Email: naeem_khan_onlyone@yahoo.com

Peer-review under responsibility of $4^{\text {th }}$ Asia International Conference 2018 editorial board

(http://www.utm.my/asia/our-team/)

(C) 2018 Published by Readers Insight Publisher,

lat 306 Savoy Residencia, Block 3 F11/1,44000 Islamabad. Pakistan,

info@ readersinsight.net

This is an open access article under the CC BY-NC-ND license (http://creativecommons.org/licenses/by-nc-nd/4.0/). 


\section{Research High Iight s}

Corporate social responsibility and corporate performance perspectives have been focal area of interest for the researchers; and as such; it has been well explored in the literature in the recent decade (Saeidi et al., 2014). Owing to the contradictory results reported by the earlier literature; Ansong and Agyemang (2017) concluded that the reason for the conflicting results is the ignorance of some relevent mediating variables. Blasi et al. (2018) stated that the association of CSR and corporate performance is still unconcluded. As a first attempt Bitar and Belnemlih (2016) captured any possible association between CSR and investment efficiency. Moreover, CSR and Financial distress have been explored in isolation. So, there is a need to explore the relationship of CSR with Financial Distress and Financial Performance by taking into consideration the mediating role of Information Asymmetry, Agency Cost and Investment Inefficiency.

\section{Research Objectives}

The study intends to investigate the inter linkages among CSR, Financial Performance and Financial Distress, while trying to capture mediating effects of some relevant yet unexplored relationships. The study is an attempt to contribute significantly to the existing literature by exploring and investigating the mediating roles of three significant variables; Information Asymmetry, Agency Cost and Investment Inefficiency; that may have crucial effect between the contradictory relationship among CSR, Financial Performance and Financial Distress. Moreover; Bagh et al. (2017); argued that the significant literature exploring CSR and Corporate Performance has been coming from the developed economies, with a mere contribution from the developing part of the world. This study is an attempt to fill the gap, by not only studying the constructs in local context, to augment the earlier literature; but by adding some new dimensions to the earlier studies to identify the factors that may help in concluding and extending the earlier literature. The study will help the policy makers in that context to have a better insight of how CSR may be promoted to enhance firm performance and to reduce Financial Distress by controlling Agency Cost, Information Asymmetry and Investment Inefficiency. 


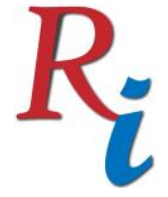

\section{Asia Proceedings of Social Sciences \\ (APSS) \\ www.readersinsight.net/APSS}

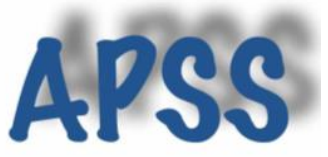

\section{Methodology}

The study design is exploratory. The study intends to identify the unexplored dimensions and dynamics of CSR that may have some direct or indirect effect on antecedant and outcomes of CSR. For this purpose an extensive literature review was conducted through meta analysis and systematic review. On the basis of findings and suggestions of the studies conducted till date, some new explorations are reported. These new arenas need to be further tested in various settings, covering developed and emerging economies. The idea is to come up with some new interventions that may extend the CSR litearure into a direction where the contradictions and inconclusions of the earlier studies may be concluded in a justifiable and generalizable outcomes. For this purpose the selected variables' literature was extensively reviewed having crucial effects on the observed and hypothesised relationships, both from the developed economies and from the developing part of the world. The study is an attempt to augment the earlier literature by adding some new dimensions to help the policy makers in that context to have a better insight of the observed dynamics of CSR.

\section{Results}

While reviewing the earlier studies through meta analysis and sytematic review, the new possible dynamics of corporate social responsibility that comes up for further investigation and empirical analysis include but are not limited to the presence of the mediating role of some relevant variables, interconnecting and affecting the studied linkages. Linkages among CSR and Financial Distress, CSR and Financial Performance, CSR and Agency Costs, CSR and Investment Inefficiency, CSR and Information Asymetry suggest the intervention of some of the variables as mediating between CSR, Financial Performance and Financial Distress. All these consructs though beeing explored in isolation are still needing some through and objective investigations to bridge the gaps of how the mutual interaction is actually gauging the performance of corporate organizations. On the basis of the factual arguments generated from the literature review it was concluded that there is a need to explore the relationship of CSR with Financial Distress and Financial Performance by taking into consideration the mediating role of Information Asymmetry, Agency Cost and Investment Inefficiency. This may help in developing an understanding of the factors contributing to the inconclusive and contradictory earlier literature. 


\section{Findings}

Corporate social responsibility and corporate performance being teh focal area of interest is still showing contradictory and inconclusive results reported by the earlier literature. This safely suggests the presence of the mediating role of some relevant variables, interconnecting and affecting the studied linkages. The review of literature leads to the need to explore the relationship of CSR with Financial Distress and Financial Performance by taking into consideration the mediating role of Information Asymmetry, Agency Cost and Investment Inefficiency. This may help in developing an understanding of the factors contributing to the inconclusive and contradictory earlier literature

\section{References}

Agyemang, O. S., \& Ansong, A. (2017). Corporate social responsibility and firm performance of Ghanaian SMEs: Mediating role of access to capital and firm reputation. Journal of Global Responsibility, 8(1), 47-62.

Blasi, S., Caporin, M., \& Fontini, F. (2018). A Multidimensional Analysis of the Relationship Between Corporate Social Responsibility and Firms' Economic Performance. Ecological Economics, 147, 218-229.

Benlemlih, M., \& Bitar, M. (2016). Corporate social responsibility and investment efficiency. Journal of Business Ethics, 148(3), 647-671.

Bagh, T., Khan, M. A., Azad, T., Saddique, S., \& Khan, M. A. (2017). The Corporate Social Responsibility and Firms' Financial Performance: Evidence from Financial Sector of Pakistan. International Journal of Economics and Financial Issues, 7(2), 301-308.

Saeidi, S. P., Sofian, S., Saeidi, P., Saeidi, S. P., \& Saaeidi, S. A. (2014). How does corporate social responsibility contribute to firm financial performance? The mediating role of competitive advantage, reputation, and customer satisfaction. Journal of Business Research, 68(2), 341-350. 